\title{
A conservative approach in selected cases of late diagnosed oesophageal perforation
}

\author{
C. A. VERWOERD, F. VAN MAZIJK, AND J. M. MEYER
}

From the Department of Thoracic Surgery, University of the Orange Free State, Bloemfontein, Republic of South Africa

Verwoerd, C. A., van Mazijk, F., and Meyer, J. M. (1977). Thorax, 32, 232-234. A conservative approach in selected cases of late diagnosed oesophageal perforation. A conservative method is presented for the treatment of oesophageal perforation where the diagnosis has been delayed. A system of tubes is described which allows the patient to be fed and at the same time prevents swallowed material from reaching the fistula. A case is reported which was successfully managed using the method.

The importance of early diagnosis and prompt surgical treatment of perforation of the oesophagus cannot be overstated. Sawyers et al. (1975) found that the mortality increased fourfold when treatment was delayed for longer than 24 hours. When the diagnosis is made late, attempts at direct suture frequently fail. Closure of the perforation in such circumstances may be achieved by the use of patch procedures employing various tissues such as pleura (Grillo and Wilkins, 1975) or stomach (Thal and Hatafuku, 1964). Such measures involve thoracotomy and, sometimes, as for instance in the patient to be described later, the general condition of the patient may be such that no major surgery can be contemplated. We describe here a system of tubes for the conservative mangement of such patients. The system is designed to remove swallowed material from the oesophagus before it reaches the perforation and to provide an easy means of feeding the patient over a period of several weeks.

The method involves the introduction of tubes through a gastrostomy. Three tubes are used (Fig. 1): (1) a Portex no 11 'blue line' endotracheal tube with an inflatable cuff; (2) an Argyle no 24 thoracic drainage tube; and (3) a Ryle's no 14 stomach tube.

Figure 2 shows the manner in which the tube system is assembled and its eventual position in the oesophagus and stomach. The Argyle and Ryle's tubes are passed through the endotracheal tube which forms a sheath leading them into the stomach. As the Argyle tube is destined to pass up the oesophagus from the stomach, a length of it is brought through the endotracheal tube such as is judged will reach from the stomach to the upper oesophagus. A shorter length of the Ryle's tube is made to project beyond the end of the endotracheal tube. The residual space in the endo- $\frac{\partial}{0}$ tracheal tube is filled with quick setting plastic.

\section{Method of insertion}

An oesophageal bougie is passed via a rigid oesophagoscope into the stomach and brought out through the gastrostomy. It is then wedged firmly into the end of the Argyle tube. The bougie is withdrawn upwards, pulling the Argyle tube up the oesophagus with it so that the latter comes to lie with its upper end in the upper part of the 3 . oesophagus and above the perforation. A tug on the bougie dislodges it from the Argyle tube. The bougie is withdrawn. 'The Ryle's tube then lieso in the stomach. Slight traction on the endotracheal tube enables its inflated cuff to seal off the gas trostomy. The Argyle tube is connected to an underwater seal to which $10 \mathrm{mmHg}$ suction iser applied so as to remove secretions from then oesophagus above the perforation. Nutrition is maintained by feeding through the Ryle's tube.

The tube system may have to be changed at weekly intervals as gastric juice tends to erode the cuff of the Portex tube.

An essential part of the treatment is the effective drainage of one or both pleural cavities.

\section{Case report}

A 35-year-old white woman was admitted on $25^{\circ}$

January 1975 . She was known to have had a corro-o 


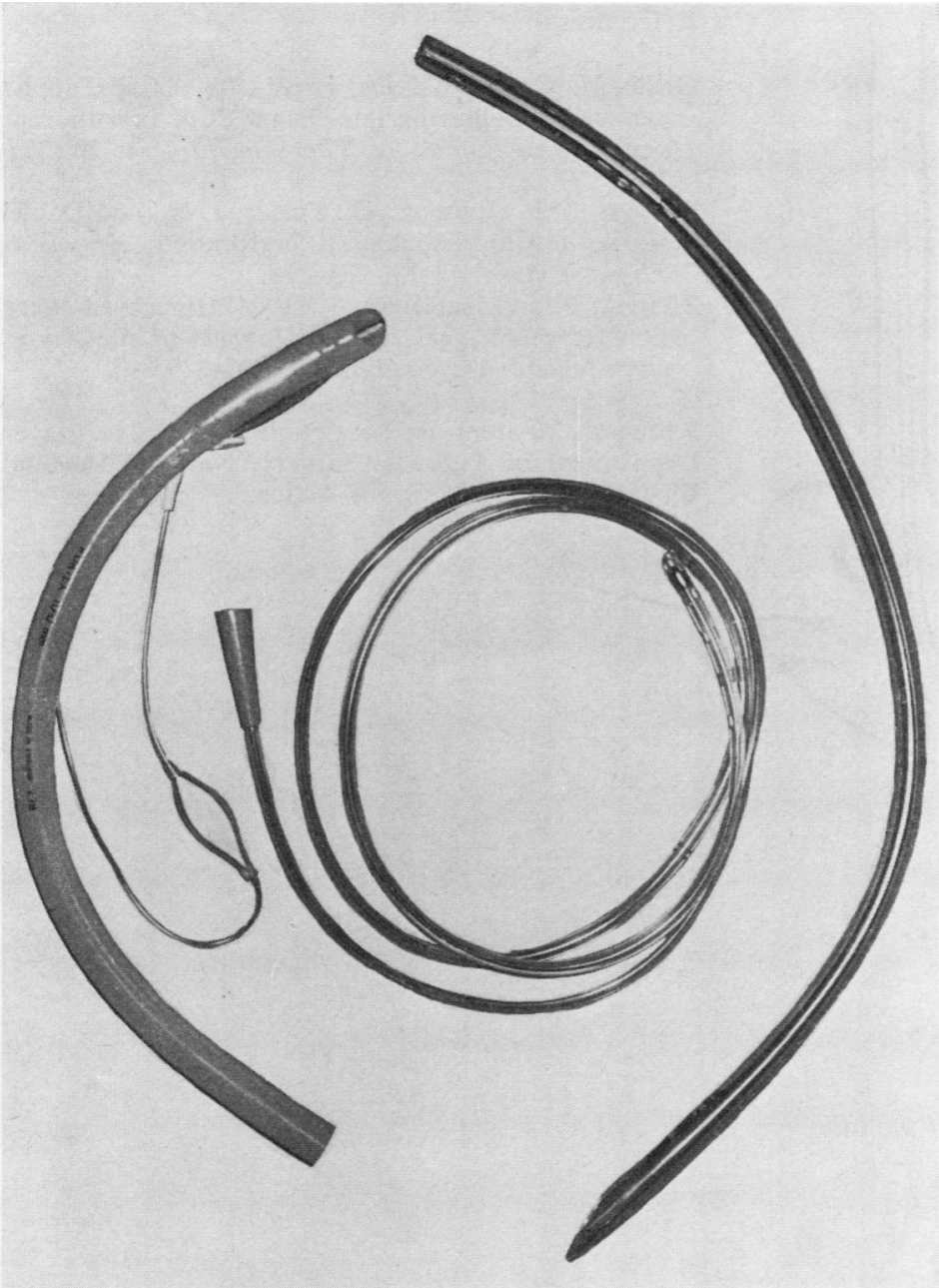

Fig. 1 From left to right: Portex endotracheal tube, Ryle's tube, and Argyle thoracic catheter.

sive stricture of the oesophagus since childhood. Twelve days before admission she had swallowed a large vitamin tablet and then developed dysphagia, regurgitation of saliva, and chest pain. The tablet, lying at $25 \mathrm{~cm}$, was removed at oesophagoscopy. Eighteen hours later the patient became febrile and a chest radiograph showed a hydropneumothorax on the right side. At thoracotomy a $2-\mathrm{cm}$ tear in the oesophagus was sutured and the pleural cavity drained. Ten days later fluids were given by mouth but there was leakage at the site of the perforation and an empyema developed. A gastrostomy was done and the empyema was drained. Four weeks later a second attempt was made to close the perforation by bringing an intercostal muscle bundle over it. This operation also failed. By this time the patient was in very poor condition. The tube system described above was introduced. Within three days the temperature and the white cell count had returned to normal. The patient's general condition improved rapidly. After five weeks a gastrografin swallow showed no leakage. Oral feeding was resumed and all drainage was discontinued. Thirteen months after discharge the patient is healthy and active and living a normal life.

\section{Discussion}

An oesophageal perforation may heal with the use of a nasogastric tube alone but we would suggest that in especially difficult situations where, as in the above case, the fistula has become chronic there is an added advantage in aspirating the oesophageal contents from above the site of the perforation. 


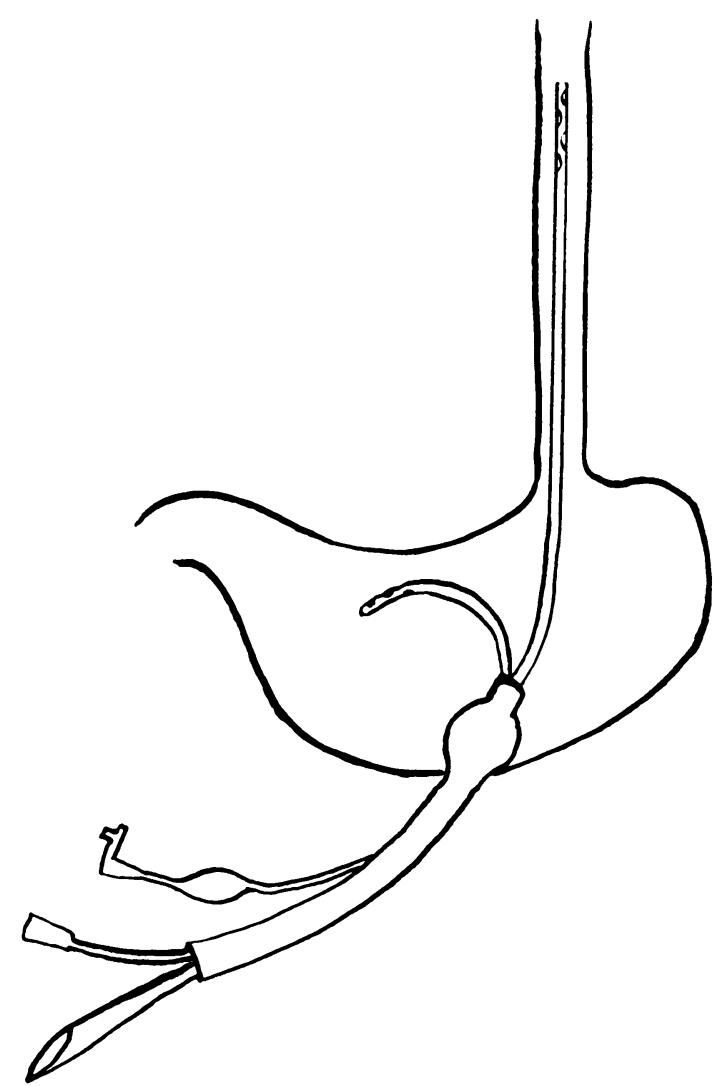

\section{References}

Grillo, H. C. and Wilkins, E. W., Jr. (1975). Esophageal repair following late diagnosis of intrathoracic perforation. Annals of Thoracic Surgery, 20, 387- $\frac{\text { s }}{\overrightarrow{0}}$ 399.

Sawyers, J. L., Lane, C. E., Foster, J. H., and Daniel, R. A. (1975). Esophageal perforation. Annals of ${ }^{\text {s }}$ Thoracic Surgery, 19, 233-238.

Thal, A. P. and Hatafuku, T. (1964). Improved operation for esophageal rupture. Journal of the Ameri- $\vec{\omega}$ can Medical Association, 188, 826-828.

Requests for reprints to: Professor J. M. Meyer, $\dot{\omega}^{-}$ Department of Thoracic Surgery, National Hospital, i Bloemfontein, 9300, South Africa.

Fig. 2 Diagram showing the position of the tube system during use.

\section{E D I C A L E D I T O R}

The Editorial Committee of Thorax thanks

Colin Ogilvie for his many services to the journal during seven years as medical editor.

$\mathrm{He}$ is succeeded by Anthony Seaton. 